\title{
Article \\ Mechanical Properties of Green Synthesized Graphene Nano-Composite Samples
}

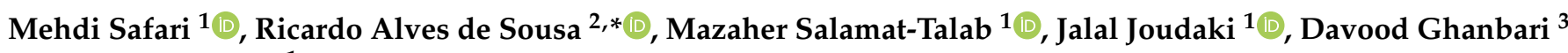 \\ and Amir Bakhtiari ${ }^{1}$ \\ 1 Department of Mechanical Engineering, Arak University of Technology, Arak 38181-41167, Iran; \\ m.safari@arakut.ac.ir (M.S.); salamattalab@arakut.ac.ir (M.S.-T.); joudaki@arakut.ac.ir (J.J.); \\ amirbakhtiyari_ed@yahoo.com (A.B.) \\ 2 Center for Mechanical Technology and Automation, Department of Mechanical Engineering, \\ Campus de Santiago, University of Aveiro, 3810-183 Aveiro, Portugal \\ 3 Department of Science, Arak University of Technology, Arak 38181-41167, Iran; d-ghanbari@arakut.ac.ir \\ * Correspondence: rsousa@ua.pt; Tel./Fax: +351-234-378-176
}

check for updates

Citation: Safari, M.; de Sousa, R.A.; Salamat-Talab, M.; Joudaki, J.; Ghanbari, D.; Bakhtiari, A. Mechanical Properties of Green Synthesized Graphene Nano-Composite Samples. Appl. Sci. 2021, 11, 4846. https://doi.org/ 10.3390/app11114846

Academic Editors: David G. Calatayud and Boyang Mao

Received: 24 April 2021

Accepted: 21 May 2021

Published: 25 May 2021

Publisher's Note: MDPI stays neutral with regard to jurisdictional claims in published maps and institutional affiliations.

Copyright: (c) 2021 by the authors. Licensee MDPI, Basel, Switzerland. This article is an open access article distributed under the terms and conditions of the Creative Commons Attribution (CC BY) license (https:// creativecommons.org/licenses/by/ $4.0 /)$.

\begin{abstract}
Graphene quantum dots are zero-dimensional nanoparticles that are used widely in advanced composite materials such as filtration membranes, adsorbent materials, optical devices, biomedical applications (especially biosensors), flame retardancy, and automotive, aerospace, agricultural and environmental applications. In this article, the mechanical properties (flexural strength, flexural strain and elastic modulus) of polymer-based nanocomposites will be investigated. The main novelty of the current work is the green synthesis of graphene quantum dots which were extracted from lemon juice. XRD and FTIR tests have been conducted to determine the composition of the prepared powder. The polyester resin and graphene quantum dots were mixed with different weight percentages $(0.25 \%, 0.5 \%$ and $1 \%$ wt. graphene) and processed to fabricate nanocomposite samples. The mechanical properties of the prepared samples were measured according to the ASTM D790-17 standard testing method. The experimental results show that the strength increased from $80 \mathrm{MPa}$ to about $112 \mathrm{MPa}$ ( $40 \%$ increase in strength) by adding $0.25 \%$ wt. graphene quantum dots. The flexural modulus decreased from 2.70 GPa to 2.06 GPa by adding $1 \%$ wt. graphene content ( $23 \%$ decrease). The flexural strain increased considerably (up to $14.2 \%$ ) by adding $1 \% \mathrm{wt}$. graphene quantum dots. Consequently, the ductility of the nanocomposites increased by adding green synthesized graphene quantum dots. The fracture behavior changed from brittle fracture mode to ductile fracture mode by adding the graphene quantum dots. Additionally, a flame retardancy test has been carried out by implementing the UL-94 test. The fabricated nanocomposites showed fire retardancy due to char barrier formation on the surface of the nanocomposites.
\end{abstract}

Keywords: polymer-based nanocomposites; graphene; green synthesize; nanoparticles; flexural properties

\section{Introduction}

Graphene is a one-atom-thick 2D honeycomb structure of carbon atoms with extra high in-plane elastic stiffness and electrical and thermal conductivities. Graphene's density equals $2.1 \mathrm{~g} / \mathrm{cm}^{3}$, and it has been investigated widely by researchers since 2004 . Graphene-based nanocomposites can be used in different industries. Graphene is one of the more exciting materials in the composite sectors. The graphene material shows considerably high mechanical strength (Young's modulus: 1000 GPa), high thermal conductivity (3000-5000 W/(m.K)) and good optical transparency ( 97.7\%) [1]. Because of the good mechanical, electrical and physical properties of graphene, it can be used in various industrial applications, such as solar cells, energy storage devices, sensors, photocatalysis, electrocatalysis, electronic panels, lightweight composites, lubrication, LEDs and so on [1,2]. 
Graphene oxide and polystyrene composites can decrease the friction in microelectromechanical systems (MEMS) by a self-lubricating thin film over the silicon substrate [2]. The lamellar structure results in admirable mechanical strength, a large surface area, low shear strength and high thermal conductivity [3]. Adding the proper weight percent of graphene can improve the corrosion behavior of fabricated composites, and a self-healing capacity can be observed in many cases [4-7]. The graphene enhances the durability of the polymer composites exposed to sunlight, and a 3\% mass fraction of graphene increases the service life of the polymers in products [8].

Alsalam et al. [9] studied the effect of graphene nanoplates on the electrical properties of SnSe/GNPs composites (metal matrix composite (MMC)). The results showed that the graphene was able to keep its crystallinity at short milling times, but it exhibited agglomeration and poor dispersion within the matrix. However, a long milling time increased the disorders on the graphene structure. Simultaneously, it provided good dispersion of the graphene particles, and the homogeneous distribution of graphene particles led to a considerable increase in electrical conductivity. Other investigations showed that the microstructure was another parameter affecting the properties of the fabricated nanocomposites [10].

Shokrieh et al. [11-16] published several research works about graphene nanoparticles and their effect on mechanical behavior. Shokrieh et al. [15] studied the effects of graphene nanoplatelets and graphene nanosheets on the fracture toughness and tensile epoxy resin properties. The graphene nanoplatelets were prepared from graphite powder by changing the magnetic field to achieve strong shear forces and obtain low thickness graphene particles. The results showed that a higher fracture toughness and tensile strength would be obtained using the graphene nanoplatelets compared with the graphene nanosheets.

The stiffness of graphene nanoplatelet and epoxy nanocomposites can be evaluated by theoretical approaches [11,14]. An investigation showed that the embedded graphene's longitudinal stiffness is different from that of the isolated graphene and is a function of its length. Therefore, a relationship was developed to consider the nanosize effect in macroscale [11]. A similar study was conducted by Sadeghpour et al. [17]. In addition, the stiffness of the graphene nanocomposites was predicted by combining the finite element method and micromechanics formulations. The matrix was considered a continuum phase, and each covalent bond of the graphene sheet was simulated by an equivalent structural beam. Nonlinear springs were used as Van der Waals bonds in the interphase region of the graphene and polymer. The random distribution of graphene sheets in a polymer was reached using the moduli of different graphene sheets with different sizes.

The flexural fatigue behavior is another critical parameter in mechanical properties assessment. Adding different weight fractions of graphene nanoplatelets to epoxy resin remarkably increases the fatigue life of the epoxy. The best fatigue life was obtained by adding $0.25 \mathrm{wt} . \%$ graphene [12]. Additionally, adding carbon nanofibers (hybrid nanocomposites of graphene, carbon nanofibers and epoxy resin) will significantly improve the epoxy resin's fatigue life compared with the results obtained by adding $0.25 \mathrm{wt} . \%$ graphene [16].

Arthisree and Madhuri [18] fabricated a composite consisting of polyacrylonitrile (PAN) and polyaniline (PANI) polymers and green synthesized graphene quantum dots. The graphene quantum dots were 2-50 nanometer-sized particles which had superior electrical properties, and hence it has been utilized in many energy harvesting and storage applications. The prepared composites were used to fabricate a prototype supercapacitor cell which could deliver a significantly higher current density compared with other polymeric capacitors.

Graphene nanoplatelets and nanosheets are used in the fabrication of polymeric composites. Another type of graphene nanoparticle is graphene quantum dots. Graphene quantum dots have been used extensively in recent years due to their unique structurerelated properties. Graphene quantum dots can be obtained from the green synthesis of alternative sources of carbon-like glucose powder [19], citric acid [20], corn powder [21] 
and rice husks [22]. Several studies have been conducted for reducing graphene oxide and improving the production process of graphene on a large scale [23,24]. Graphene quantum dots are environmentally friendly due to their nontoxic and biologically inert properties. Graphene quantum dots are stable chemically and physically because of their intrinsic inert carbon properties. Tian et al. [25] published a review paper. They discussed different methods of graphene quantum dot preparation such as the hydrothermal method, microwave-assisted hydrothermal method, soft template method, liquid exfoliation method, metal-catalyzed method and electron beam lithography method. Yan et al. [26] also published a review paper, and the differences between graphene quantum dots and other nanomaterials, including nano carbons, were discussed. Good mechanical, electrical and photosensitive applications can be obtained using graphene quantum dots by fabricating nanocomposite polymers. Gobi et al. studied the effect of adding graphene quantum dots to epoxy resin. The results showed that the tensile strength, Young's modulus and nominal strain at break increased by $125 \%, 153.4 \%$ and $18.1 \%$, respectively [27]. The graphene-based nanocomposites will be a starting point for new and more sophisticated composite materials.

The literature survey shows different aspects of using graphene in nanocomposite fabrication. Graphene was used as nanoplatelets and nanosheets at first. Then, by introducing graphene quantum dots, new ways for using this type of carbon atom were found. Several studies have been carried out on lemon extract to reduce the graphene oxide and graphene quantum dot synthesis. However, the synthesis of graphene quantum dots directly from the lemon extract is very novel. In this article, the effect of different weight percentages of graphene quantum dots on polyester nanocomposite fabrication will be investigated. The main difference between the current work and other implemented research is the way of preparing graphene quantum dots: green synthesis and the usage of graphene quantum dots to enhance the mechanical properties of polymer-based nanocomposites. The flexural strength, strain at the failure point and elastic modulus of the nanocomposites were measured and discussed. The flame retardancy of fabricated nanocomposites will be carried out against fire.

\section{Materials and Methods}

\subsection{Green Synthesized Graphene Quantum Dots}

For the preparation of carbon graphene particles, $10 \mathrm{~mL}$ of lemon juice $(0.01 \mathrm{~mol}$ of citric acid extract) and $0.01 \mathrm{~mol}$ of ethylenediamine were added to $200 \mathrm{~mL}$ water. The lemon juice is prepared from natural fruit. Then, the dispersion was transferred into a Teflon-lined stainless autoclave (volume: $250 \mathrm{~mL}$, manufactured in the workshop of arak university of technology, Arak, Iran) at $220{ }^{\circ} \mathrm{C}$ for $72 \mathrm{~h}$. The precipitated product was centrifuged (15,000 rpm for $30 \mathrm{~min}$ ) and washed with ethanol and deionized water. Table 1 shows the volumes of the reagents used in the green synthesis of graphene quantum dots. All of reagents prepared from products of Merck company, Darmstadt, Germany. After that, the quantum dot product $(1 \mathrm{~g})$ was dispersed in $200 \mathrm{~mL}$ of a deionized water solvent under ultrasonic waves ( $150 \mathrm{~W}$ for $60 \mathrm{~min}$ ). The ultrasonic machine provided by FAPAN company, Tehran, Iran. After the sonochemical reaction, the graphene product was centrifuged and dried in an oven $\left(70^{\circ} \mathrm{C}\right.$ for $24 \mathrm{~h}$ ). The oven was provided by Sci Finetech Co., Seoul, Korea. Figure 1 shows the schematic procedure of the green synthesis of lemon juice to produce graphene quantum dots. Figure 2 shows the chemical reaction during production of the graphene quantum dots. The citric acid $\left(\mathrm{HOC}\left(\mathrm{CO}_{2} \mathrm{H}\right)\left(\mathrm{CH}_{2} \mathrm{CO}_{2} \mathrm{H}\right)_{2}, 0.1 \mathrm{~mol}\right)$ and ethylenediamine $\left(\mathrm{C}_{2} \mathrm{H}_{4}\left(\mathrm{NH}_{2}\right)_{2}, 0.01 \mathrm{~mol}\right)$ under a higher pressure and temperature produced graphene quantum dots. There are a lot of hydroxyl and carboxyl functional groups on the surface of graphene quantum dots. Strong hydrogen bonding will be made between them and the carbonyl and ester functional groups in the polyester. The dispersion will be obtained because of the mechanical stirring, ultrasound vibration and too many branches of carbonyls, esters and hydroxyls. In the next step, different percentages of the graphene quantum dots are added to the polyester and make nanocomposite samples. 
Table 1. The reagent volumes used for graphene quantum dot synthesis.

\begin{tabular}{cc}
\hline Reagent & Volume \\
\hline Lemon juice & $10 \mathrm{~mL}(0.01 \mathrm{~mol})$ \\
Ethylenediamine $\left(\mathrm{C}_{2} \mathrm{H}_{8} \mathrm{~N}_{2}\right)$ & $0.66 \mathrm{~mL}(0.01 \mathrm{~mol})$ \\
Water & $200 \mathrm{~mL}(11.11 \mathrm{~mol})$ \\
\hline
\end{tabular}

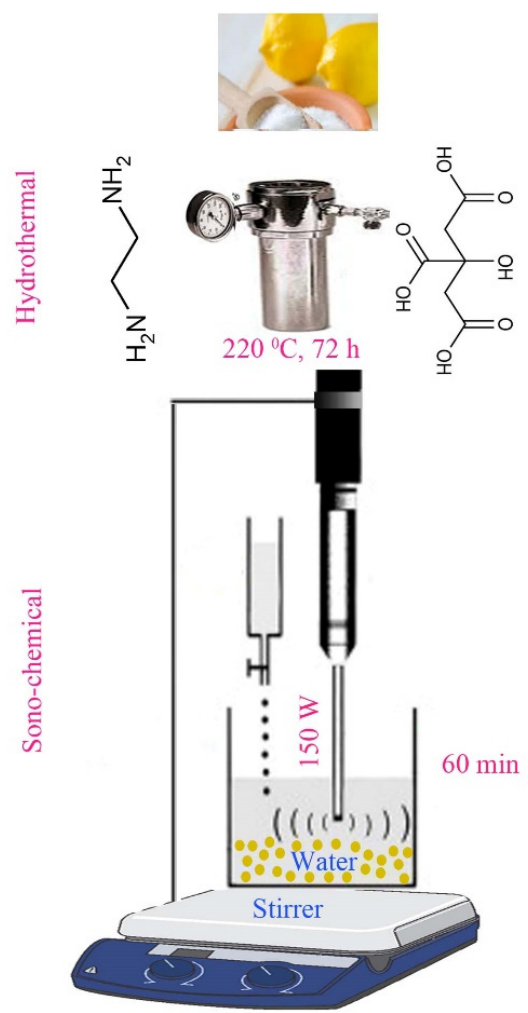

Figure 1. Green synthesis of graphene quantum dots.
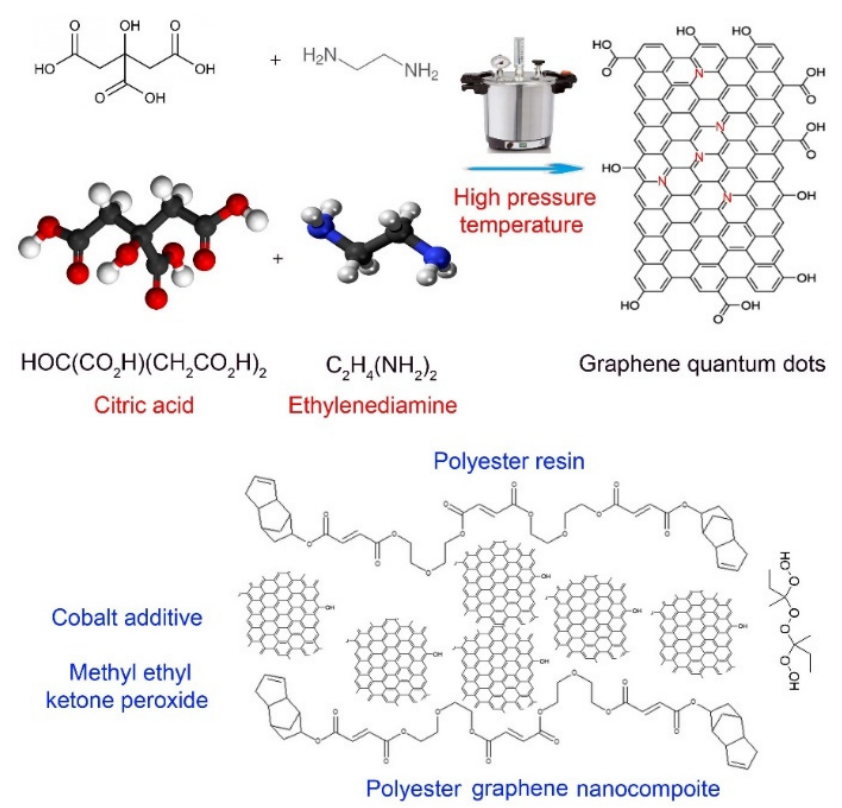

Figure 2. The chemical reaction in the green synthesis of graphene quantum dots and the fabrication of nanocomposites. 


\subsection{Sample Preparation}

After the production of graphene quantum dots by green synthesis, the polymer-based nanocomposites should be prepared. For this purpose, first, it is necessary to prepare the matrix (resin). Polyesters are a category of polymers that contain the ester functional group in their main chain. Polyesters are usually transparent, flammable and brittle materials. The prepared polyester resin from Boytec company (made in Turkey) was a thermoset polymer, which was polymerized by adding a hardener. Two different samples with and without nanoparticles should be prepared for investigation of the mechanical properties. For the preparation of samples without nanoparticles, $70 \mathrm{~g}$ of polyester resin was poured into a beaker, and $0.350 \mathrm{~g}$ of a cobalt additive ( $0.5 \% \mathrm{wt}$.) was added to it. A mechanical stirrer was utilized to stir the solution for $5 \mathrm{~min}$ at an 80 -rpm rotational speed. The solution was left in a room environment for $15 \mathrm{~min}$ (debubbling). The last step was adding methyl ethyl ketone peroxide (usually called acid or hardener) to the mixture. The $0.423 \mathrm{~g}$ of methyl ethyl ketone peroxide $(0.6 \% \mathrm{wt}$.) was added to the mixture and stirred for $3 \mathrm{~min}$ at an 80 -rpm rotational speed. The polymerization started, and after $6 \mathrm{~min}$, the mixture viscosity increased such that pouring of the die was impossible. Therefore, before ending the gelation time, the mixture would be transferred to the die. After pouring the nanocomposite mixture into the die, the die was left at room temperature for $40 \mathrm{~h}$ and then post-cured at $80^{\circ} \mathrm{C}$ for $8 \mathrm{~h}$ in an oven according to the resin producer's instructions.

For the preparation of samples with nanoparticles, a similar procedure was repeated. The green synthesized graphene quantum dots were added to the resin $(70 \pm 0.001 \mathrm{~g})$ with different weight percentages $(0.25 \%, 0.5 \%$ and $1 \% \mathrm{wt}$.). The mixture of resin and graphene was mechanically stirred for $30 \mathrm{~min}$ at a $1500-\mathrm{rpm}$ rotational speed. The mixture was sonicated for $15 \mathrm{~min}$ by a $14 \mathrm{~mm}$ in diameter probe sonicator (Hielscher UP400S) at an output power of $200 \mathrm{~W}$ and a frequency of $24 \mathrm{kHz}$. The solution was left in the room environment for $40 \mathrm{~min}$ (debubbling). The $0.350 \mathrm{~g}$ of cobalt additive $(0.5 \% \mathrm{wt}$.) was added to the mixture of styrene and graphene quantum dots and mechanically stirred for $3 \mathrm{~min}$ at an 80-rpm rotational speed. The solution was left again for $15 \mathrm{~min}$. The last step was adding methyl ethyl ketone peroxide (hardener) to the mixture. The $0.423 \mathrm{~g}$ of methyl ethyl ketone peroxide $(0.6 \% \mathrm{wt}$.) was added to the mixture and stirred for $3 \mathrm{~min}$ at an 80 -rpm rotational speed. Then, the mixture was transferred to the sample preparation die, cured at room temperature for $40 \mathrm{~h}$ and post-cured at $80^{\circ} \mathrm{C}$ for $8 \mathrm{~h}$ in an oven. Figure 3 shows the graphene nanocomposite mixture after stirring and the prepared samples with and without graphene quantum dots.

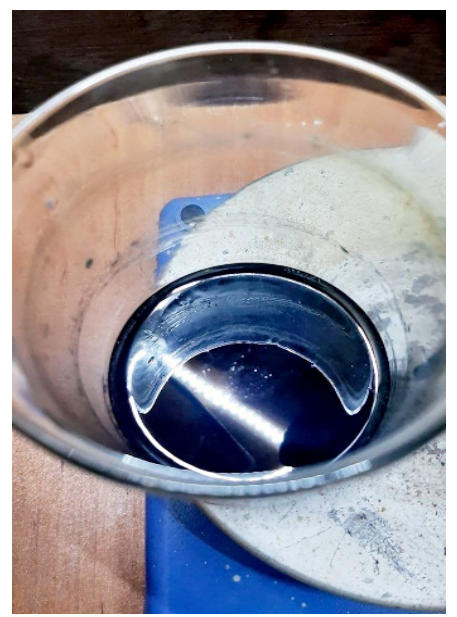

(a)

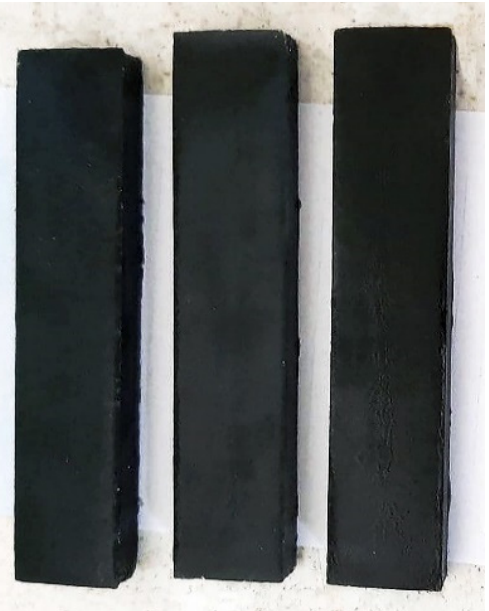

(b)

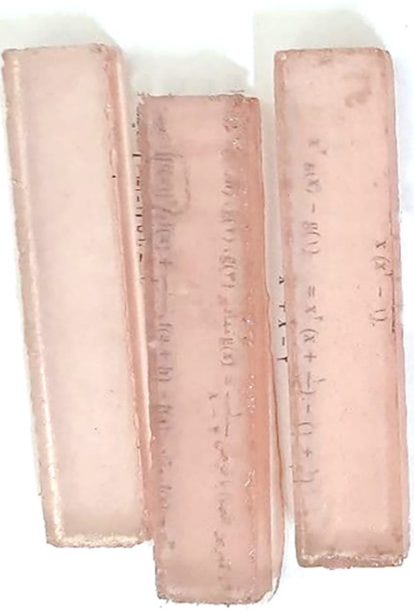

(c)

Figure 3. (a) The graphene quantum dot composite mixture, (b) the final graphene composites and (c) polyester composites (without graphene). 


\subsection{Flexural Test}

After preparation of the composite mixture, it was transferred to a die. The die consisted of cavities $100 \mathrm{~mm}$ in length and $20 \mathrm{~mm}$ wide. The mixture was poured to prepare an 8-mm thick composite sample. After post-curing, the surfaces of the hardened samples were polished with soft sandpaper. The sample was placed in a three-point bending fixture with a span length of $80 \mathrm{~mm}$. The bending test was carried out at a $3 \mathrm{~mm} / \mathrm{min}$ speed, and the force-displacement data was logged. Three samples were prepared and tested for each weight percentage of green synthesized nanocomposites. Figure 4 shows the implementation of the three-point bending test with a universal tensile testing machine.

$$
\sigma_{f}= \begin{cases}\frac{3 P L}{b d^{2}} & \text { Small Deflection } \\ \frac{3 P L}{b d^{2}}\left[1+6\left(\frac{D}{L}\right)^{2}-4\left(\frac{d}{L} \frac{D}{L}\right)\right] & \text { Large Deflection }\end{cases}
$$

where $\sigma_{f}$ is the flexural bending stress at the outer surface of the beam at the midpoint, $P$ is the load at a given point on the load-deflection curve, $L, b$ and $d$ are the fixture span, width and depth of the tested beam, respectively, and $D$ is the deflection of the centerline of the specimen at the middle of the fixture span.

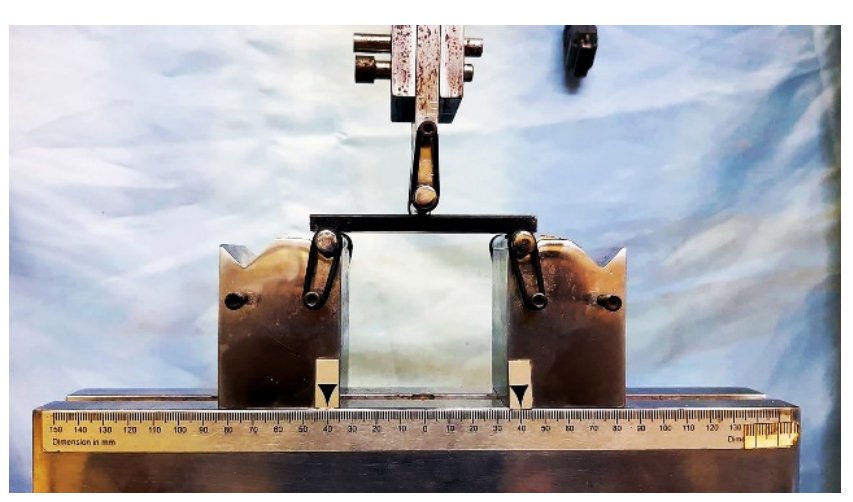

(a)

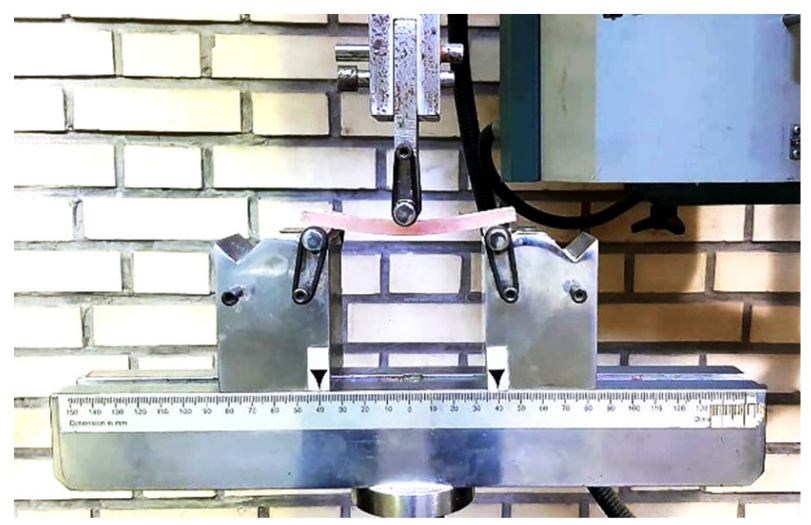

(b)

Figure 4. (a) The three-point bending fixture and (b) implementation of the bending test.

The flexural strain and tangent modulus of elasticity (which is usually called the modulus of elasticity) are two main three-point bending test parameters used to assess the beam's behavior in bending. The flexural strain $\left(\varepsilon_{f}\right)$ and modulus of elasticity $\left(E_{B}\right)$ can be calculated by Equations (2) and (3) [28]:

$$
\begin{gathered}
\varepsilon_{f}=\frac{6 d D}{L^{2}} \\
E_{B}=\frac{L^{3} m}{4 b d^{3}}
\end{gathered}
$$

where $m$ is the slope of the tangent to the initial straight line portion of the load-deflection curve.

\section{Results and Discussion}

\subsection{Green Synthesis of Graphene Quantum Dots}

The morphology and size of carbon graphene quantum dots were investigated using a scanning electron microscopy (SEM) machine. The SEM image of the green synthesized graphene quantum dots is shown in Figure 5. The results confirm that the monodispersed nanoparticles were synthesized with an average particle size of $20 \mathrm{~nm}$ (spherical dots). 
The SEM images of the fractured surface of the graphene nanocomposites are shown in Figure 6. As can be seen in Figure 6, the presence of nanoparticles on the surface of the polymer matrix increased by increasing the concentration of graphene quantum dots in the polyester matrix. The graphene quantum dots were prepared in green synthesis. The morphology of the graphene was spherical dots ( $20 \mathrm{~nm}$ average size).

Figure 7 shows the XRD pattern of the carbon graphene quantum dots. The pattern matched the standard peaks of JCPDS card No. 00-08-0415 and confirmed the graphene production.

The Fourier-transform infrared (FTIR) spectrum of the as-prepared carbon graphene dots is shown in Figure 8, with a broad and strong absorption band of about $3422 \mathrm{~cm}^{-1}$ attributed to vibration stretching in the hydroxyl group. Absorptions at 2812, 2850 and $2918 \mathrm{~cm}^{-1}$ were due to the $\mathrm{C}-\mathrm{H}$ stretching vibrations. The bands at $1633 \mathrm{~cm}^{-1}$ were related to the stretching vibration in $\mathrm{C}=\mathrm{O}$. The bands at 1383 and $1576 \mathrm{~cm}^{-1}$ were attributed to the $\mathrm{C}=\mathrm{C}$ bonds. The absorption band at $1042 \mathrm{~cm}^{-1}$ was for stretching vibrations in $\mathrm{C}-\mathrm{O}$, while the bands obtained at 798 and $760 \mathrm{~cm}^{-1}$ were attributed to yjr stretching vibration in C-C [29-31].

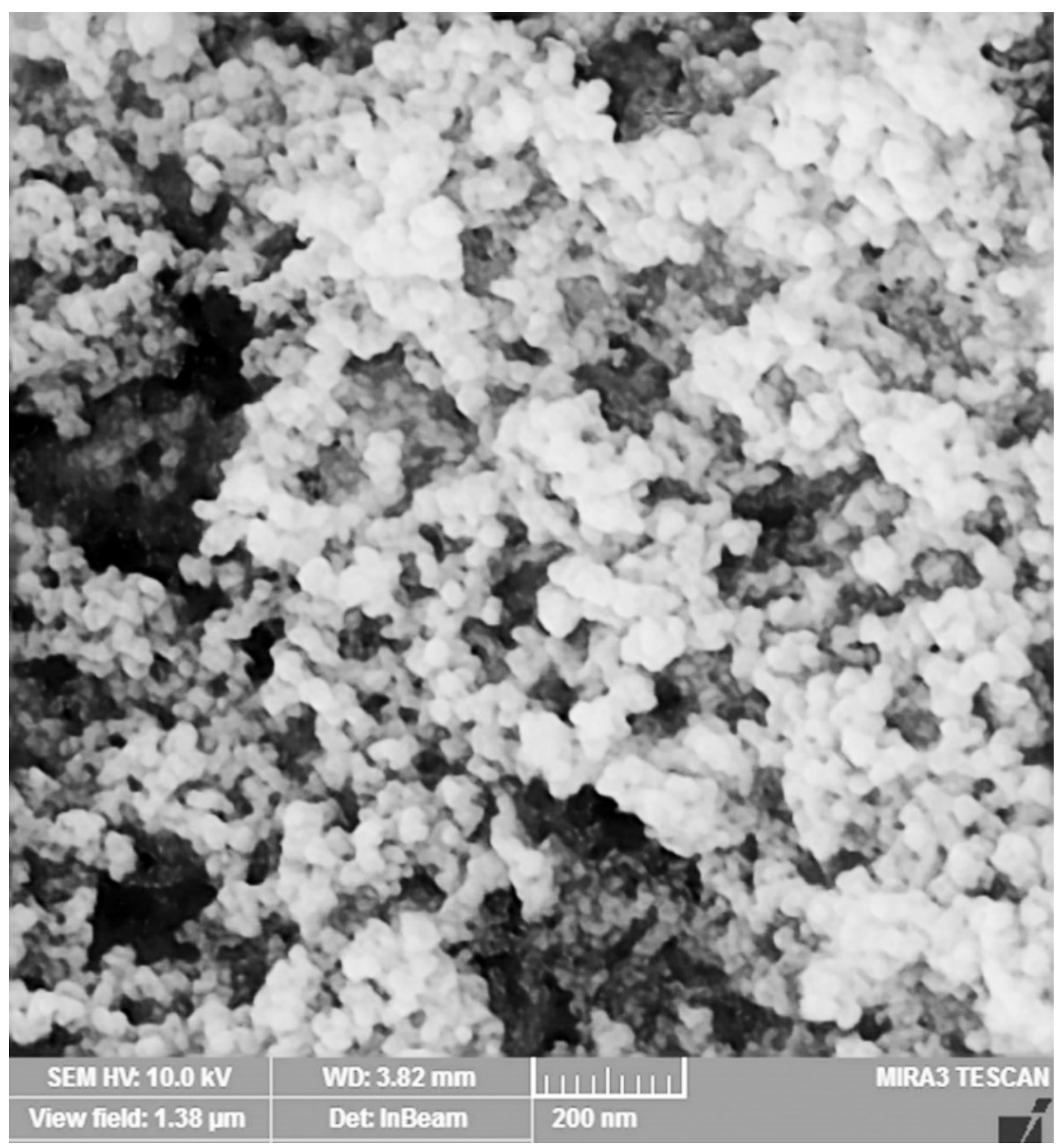

Figure 5. SEM image of carbon graphene dots. 


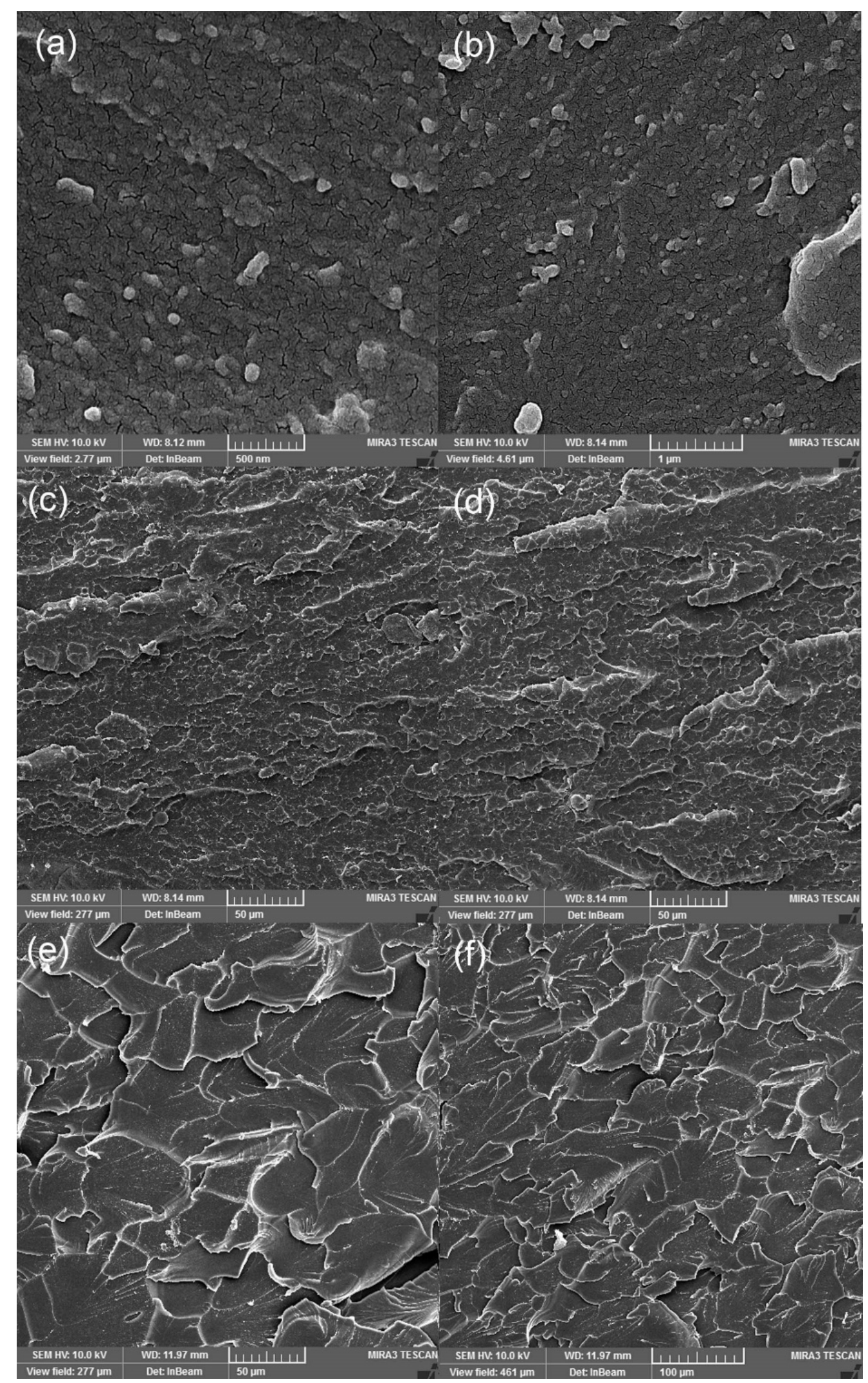

Figure 6. Micrograph of the fracture cross-section for $(\mathbf{a}, \mathbf{b}) 0.25 \% \mathrm{wt} .,(\mathbf{c}, \mathbf{d}) 0.5 \% \mathrm{wt}$. and $(\mathbf{e}, \mathbf{f}) 1 \% \mathrm{wt}$. graphene quantum dots. 


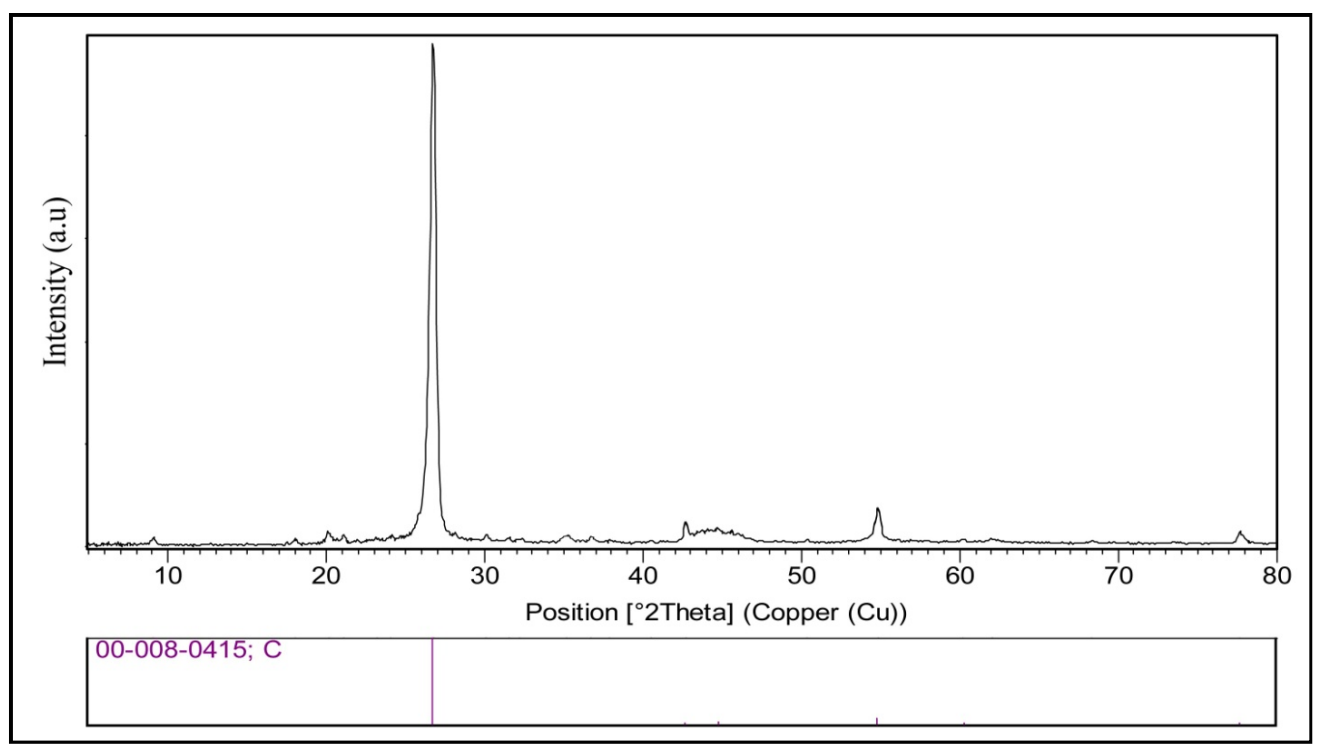

Figure 7. XRD pattern of carbon graphene quantum dots.

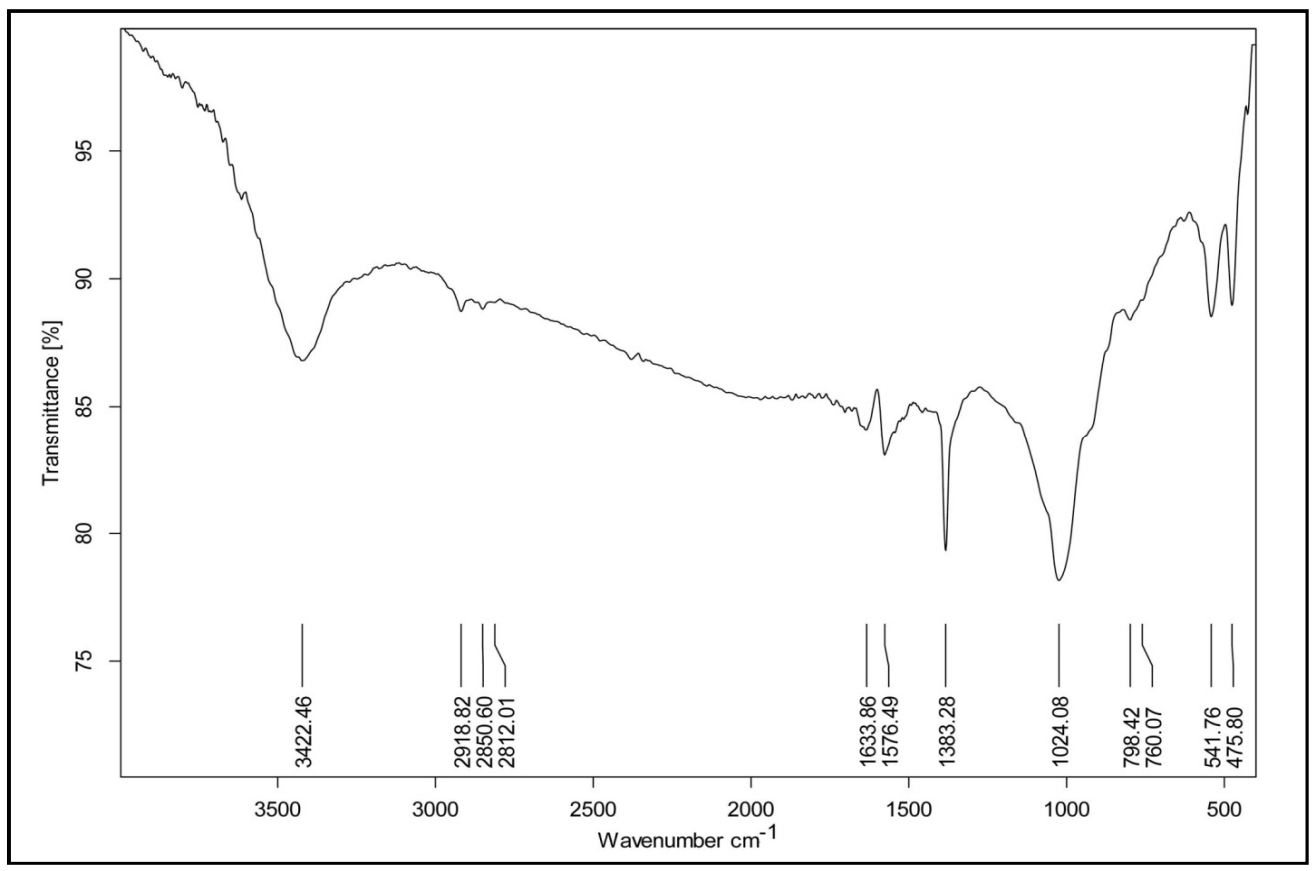

Figure 8. FTIR spectrum of the nanocomposites.

The influence of graphene quantum dot additives on the fire retardancy of the polymer resin was examined applying the UL-94 test (a sample of $130 \times 13 \times 1.6 \mathrm{~mm}$ was used). A flame $(1.5 \mathrm{~cm})$ was applied to the specimen (time: $10 \mathrm{~s}$ ) twice. When the sample extinguished in less than $10 \mathrm{~s}$ after fire ignition, it was in a V-0 class (drips are allowed as long as they are not inflamed). A V-1 type is for a sample with a fire time of less than $30 \mathrm{~s}$ (drips are like those in the V-0 class). The V-2 class has a fire time like the V-1 class while flaming drips are permitted. When the total flaming time is above $50 \mathrm{~s}$, it is not classified (NC). Finally, horizontal burning with a rate of less than $76 \mathrm{~mm} / \mathrm{min}$ is HB [29-31].

The UL-94 test for the pure polymer was NC, while the nanocomposites were confirmed for V-1 classification (Figure 9). Fire retardancy of the nanocomposites was due to the high surface-to-volume ratio, which dispersed into the matrix homogeneously, and the formation of a char barrier during combustion. This barrier decreased the evaporation of organic components and reduced the oxygen and flame reaching the sample. 


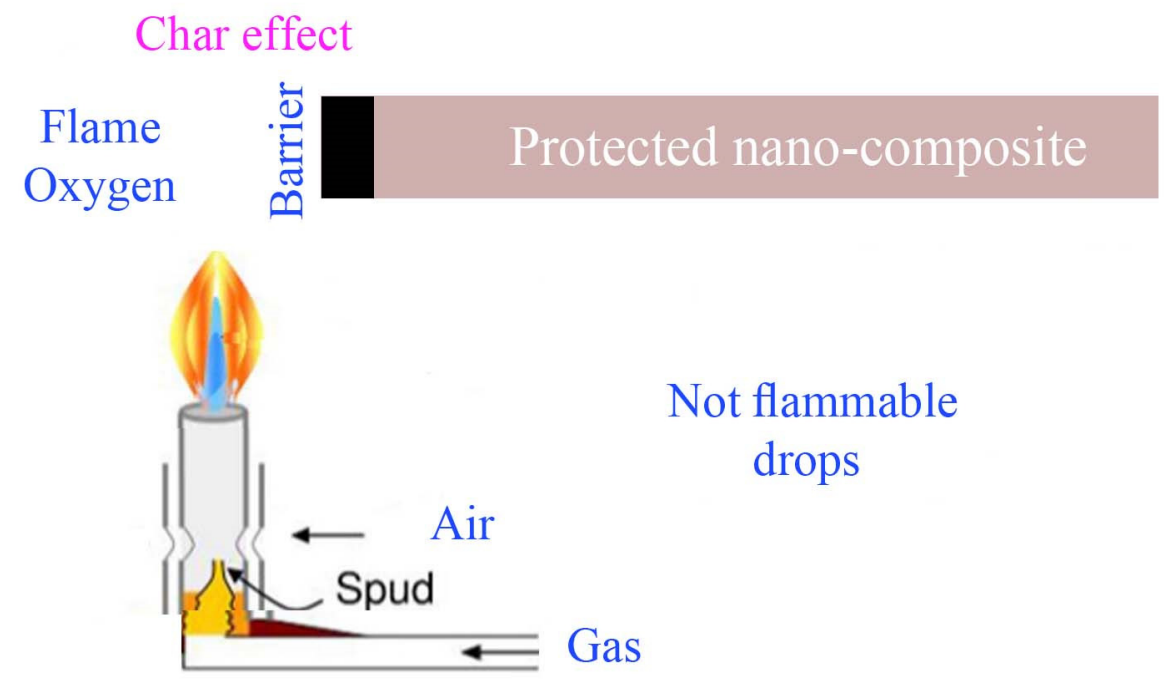

Figure 9. Schematic of the UL-94 test of the polymeric nanocomposites.

Limiting oxygen index (LOI) analysis of the $0.25,0.5$ and $1 \%$ wt. graphene quantum dots was implemented and is shown in Table 2 . The results showed that by increasing the nanoparticle concentration, the LOI value increased from 17 to 22 (29.4\% enhancement), and fire retardancy was also improved. In addition, other investigations on adding nanoparticles (carbon nanostructure, multi-walled carbon nanotubes (MWCNT) to polyester showed that the flame retardancy of the nanocomposites improved, and thermal decomposition of the nanocomposites was shifted toward higher temperatures [32-34].

Table 2. The limiting oxygen index (LOI) for different graphene weight percentages.

\begin{tabular}{cc}
\hline Sample & Limiting Oxygen Index (LOI) \\
\hline Pure polyester resin & 17 \\
Polyester resin, 0.25\% wt. of graphene & 18 \\
Polyester resin, 0.5\% wt. of graphene & 20 \\
Polyester resin, 1\% wt. of graphene & 22 \\
\hline
\end{tabular}

\subsection{Flexural Properties}

Figure 10 shows the load-displacement curve for the different prepared samples. The slope of the tangent to the initial straight line is the $m$ coefficient in Equation (3). Figure 11a,b shows the modulus of elasticity (flexural modulus), flexural strength and flexural strain (strain at failure point) for different weight percentages of the graphene quantum dots. The results showed that adding $0.25 \% \mathrm{wt}$. of the graphene quantum dots increased the strength from $80 \mathrm{MPa}$ to about $112 \mathrm{MPa}$ (40\% increase in strength). Adding a greater percentage of graphene quantum dots would not increase the flexural strength meaningfully. The flexural modulus decreased from $2.70 \mathrm{GPa}$ to 2.39, 2.38 and $2.06 \mathrm{GPa}$ by adding $0.25,0.5$ and $1 \%$ wt. graphene content, respectively. The flexural modulus decreased up to $23 \%$ for the $1 \% \mathrm{wt}$. graphene. Figure $11 \mathrm{c}$ shows the flexural strain (strain at failure point) for the different tested samples. The flexural strain increased considerably. The neat polyester deformed to 3.11\% strain, which shows a brittle fracture in the materials. By adding the $0.25,0.5$ and $1 \%$ wt. graphene, the strain increased to $7.81,8.35$ and $14.20 \%$, respectively. The stress-strain behavior of the three-point bending test shows that adding green synthesized graphene quantum dots increased the strength and ductility of the nanocomposites, and the fracture behavior changed from brittle to ductile. By increasing the flexural strength and flexural strain and decreasing the modulus of elasticity, the composite samples could absorb significantly higher energy before failure (ductility). Cracks propagated with a lower growth rate. This was mainly because the nanoparticles decreased the crack growth rate. Crack deflection, particle debonding and plastic void 
growth are three main mechanisms of failure in nanocomposites [35]. The crack growth direction changes when it receives the nanoparticles, and the micro-void coalescence is retarded. The error bar of the flexural modulus, flexural strength and flexural strain was considerably low. Several pieces of research have been published about the improvement of the mechanical properties of composites by adding nanoparticles. As a special case, Shokrieh et al. [36,37] improved the flexural strength of polyester nanocomposites by about $18 \%$ using multi-wall carbon nanotubes (CNT). Additionally, various carbon-based nano-additives were applied in the polymer nanocomposites, but to the best knowledge of the present authors, this article is the first attempt at using green synthesized graphene quantum dots to enhance the mechanical properties of nanocomposites. As the results show, considerable enhancement in the flexural behavior and strain at failure was obtained.

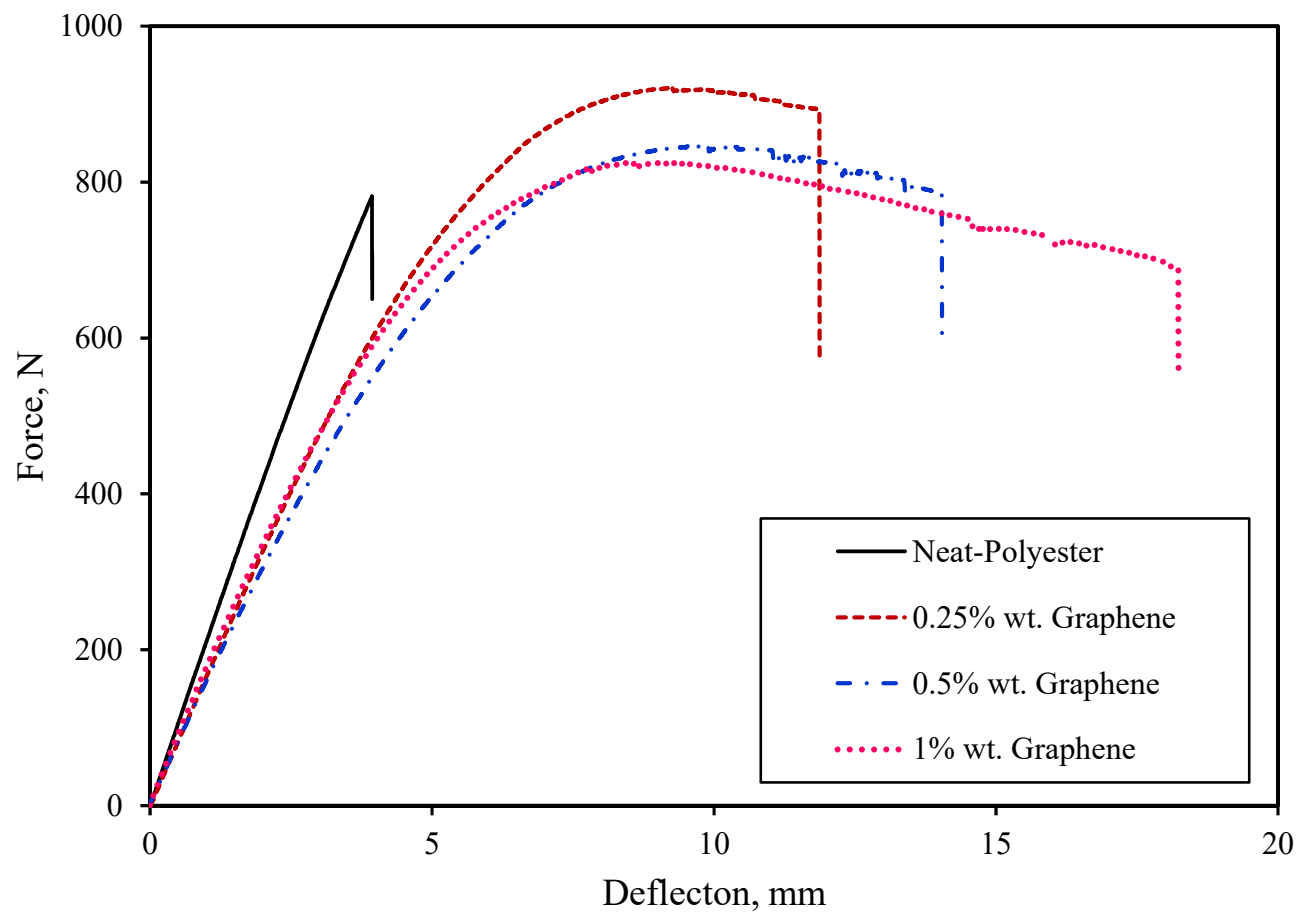

Figure 10. The load-displacement for the neat polyester $0.25,0.5$ and $1 \% \mathrm{wt}$. graphene quantum dot composites.

The uniformity of dispersion of graphene quantum dots is important in composite fabrication. The agglomeration of graphene quantum dots decreases the strength of the composite by the formation of secondary bonding interactions between the graphene quantum dots rather than the primary bonding with the matrix [27]. Production of graphene quantum dots by green synthesis is a very cheap method compared with other synthesis processes. This article focuses on the feasibility of using green synthesis for the production of composite parts and studying the effect of adding graphene quantum dots on the mechanical properties of the fabricated parts. New research should be conducted to investigate different aspects of the green synthesis process parameters, including the initial material of graphene extraction (such as turmerics or potatoes), interface formation between the nanoparticles and the matrix and different sonication times, dispersions and aggregations of graphene powder, which is the ongoing project of the authors. 


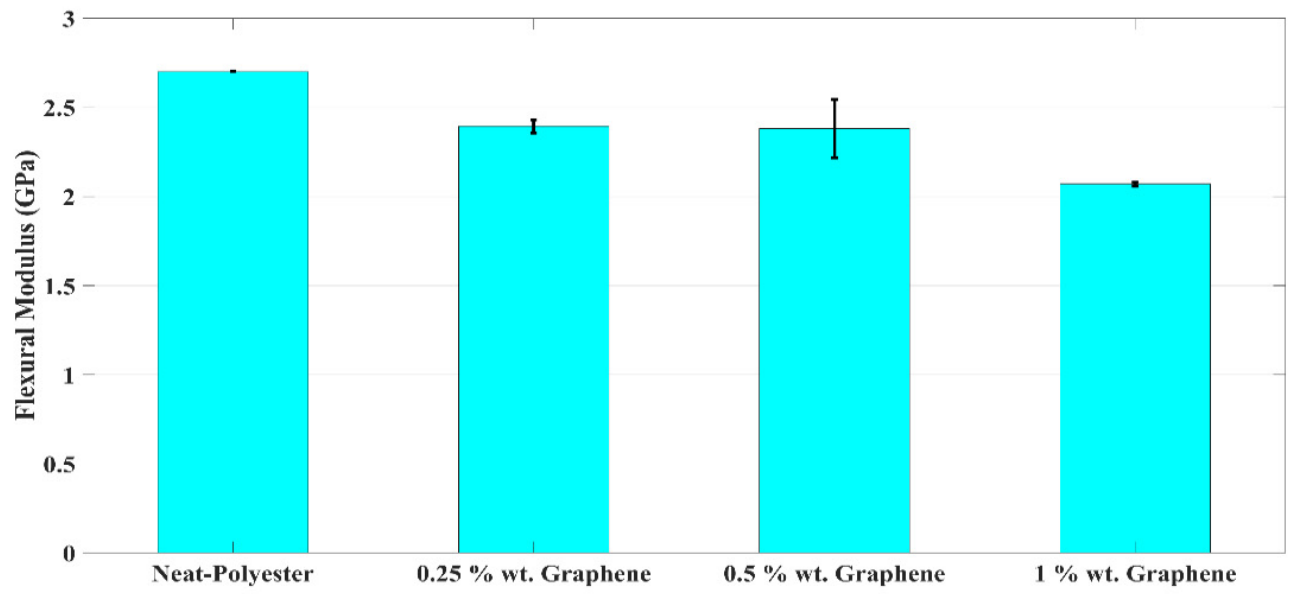

(a)

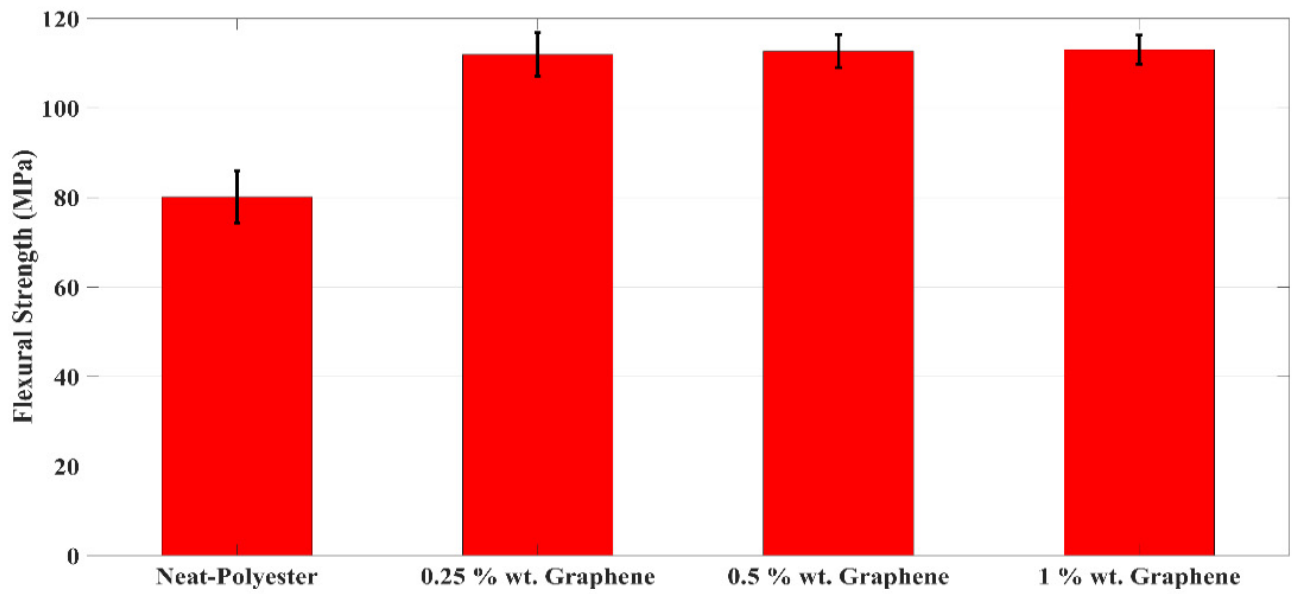

(b)

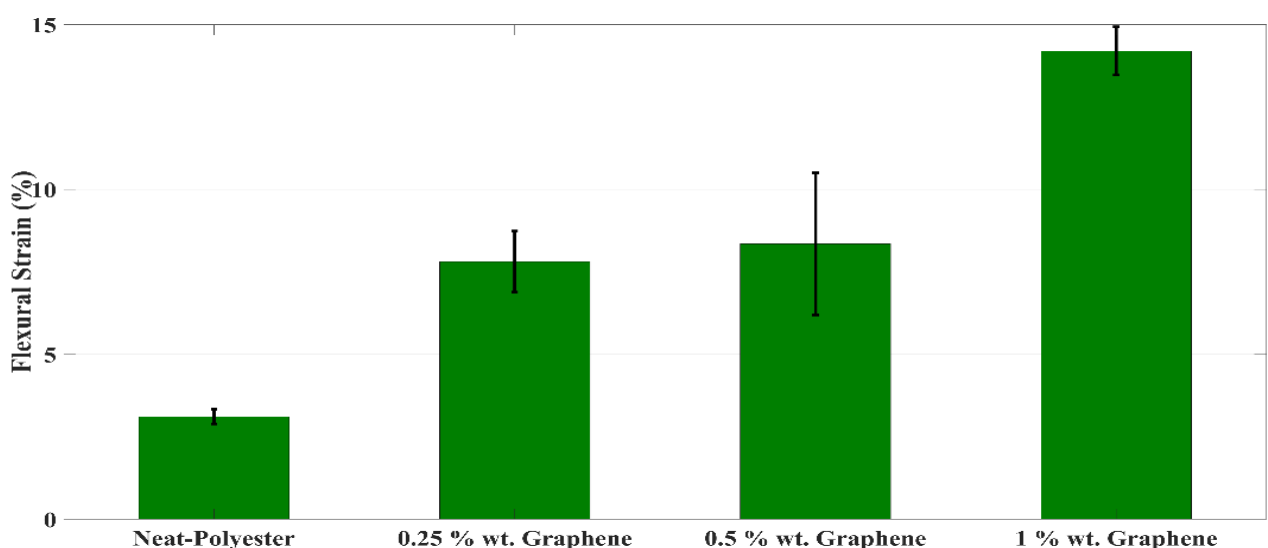

(c)

Figure 11. (a) Flexural modulus, (b) flexural strength and (c) flexural strain for the graphene quantum dot composites. 


\section{Conclusions}

Graphene nanocomposites are used widely in different industries. The production of graphene for large-scale applications is still a major challenge. In this article, graphene quantum dots were produced by green synthesis. The graphene quantum dots were extracted from lemon juice at a cheap cost. XRD and FTIR testing proved the production of graphene quantum dots. The results of the three-point bending test for $0.25,0.5$ and $1 \%$ wt. graphene showed that adding the graphene quantum dots increased the strength from $80 \mathrm{MPa}$ to about $112 \mathrm{MPa}$ ( $40 \%$ increase in strength). The flexural modulus decreased from $2.70 \mathrm{GPa}$ to $2.06 \mathrm{GPa}$ by adding the $1 \%$ wt. graphene content ( $23 \%$ decrease). The flexural strain increased considerably, and the fracture mode changed from a brittle fracture to a ductile fracture by adding the graphene quantum dots. The prepared nanocomposites showed fire retardancy. The produced graphene quantum dots showed acceptable improvement in the mechanical properties, while the graphene powder was obtained very easily and in an environmentally friendly manner.

Author Contributions: Conceptualization, M.S.; formal analysis and funding acquisition, R.A.d.S.; investigation and methodology, M.S.-T. and D.G.; test implementation, M.S.-T. and A.B.; validation and writing-original draft preparation, J.J.; writing-review and editing, M.S., R.A.d.S., M.S.-T., D.G. and J.J. All authors have read and agreed to the published version of the manuscript.

Funding: Ricardo J. Alves de Sousa acknowledges grants UID/EMS/0048 CENTRO-01-0145-FEDER022083-Centro2020 from the European Regional Development Fund (ERDF).

Institutional Review Board Statement: Not applicable.

Informed Consent Statement: Not applicable.

Data Availability Statement: Data are contained within the article.

Conflicts of Interest: The authors declare no conflict of interest.

\section{References}

1. Das, T.K.; Prusty, S. Graphene-based polymer composites and their applications. Polym. Plast. Technol. Eng. 2013, 52, 319-331. [CrossRef]

2. Chouhan, A.; Sarkar, T.K.; Kumari, S.; Sivakumar, K.L.N.; Sugimura, H.; Khatri, O.P. Mechano-adaptive thin film of graphenebased polymeric nanocomposite for enhancement of lubrication properties. Appl. Surf. Sci. 2021, 538, 148041. [CrossRef]

3. Huang, X.; Zhi, C.; Lin, Y.; Bao, H.; Wud, G.; Jiang, P.; Mai, Y.W. Thermal conductivity of graphene-based polymer nanocomposites. Mater. Sci. Eng. R. Rep. 2020, 142, 100577. [CrossRef]

4. Ye, Y.; Zhang, D.; Liu, T.; Liu, Z.; Pu, J.; Liu, W.; Zhao, H.; Li, X.; Wang, L. Superior corrosion resistance and self-healable epoxy coating pigmented with silanzied trianiline-intercalated graphene. Carbon 2019, 142, 164-176. [CrossRef]

5. Hikku, G.S.; Jeyasubramanian, K.; Venugopal, A.; Ghosh, R. Corrosion resistance behaviour of graphene/polyvinyl alcohol nanocomposite coating for aluminium-2219 alloy. J. Alloys Compd. 2017, 716, 259-269. [CrossRef]

6. Wu, Y.; Zhu, X.; Zhao, W.; Wang, Y.; Wang, C.; Xue, Q. Corrosion mechanism of graphene coating with different defect levels. J. Alloys Compd. 2019, 777, 135-144. [CrossRef]

7. Jiang, F.; Zhao, W.; Wu, Y.; Dong, J.; Zhou, K.; Lu, G.; Pu, J. Anti-corrosion behaviors of epoxy composite coatings enhanced via graphene oxide with different aspect ratios. Prog. Org. Coat. 2019, 127, 70-79. [CrossRef]

8. Goodwin, D.G., Jr.; Shen, S.J.; Lyu, Y.; Lankone, R.; Barrios, A.C.; Kabir, S.; Perreault, F.; Wohlleben, W.; Nguyen, T.; Sung, L. Graphene/polymer nanocomposite degradation by ultraviolet light: The effects of graphene nanofillers and their potential for release. Polym. Degrad. Stab. 2020, 182, 109365. [CrossRef]

9. Alsalama, M.; Hamoudi, H.; Youssef, K.M. The Effect of Graphene Structural Integrity on the Power Factor of Tin Selenide Nanocomposite. J. Alloys Compd. 2021, 872, 159584. [CrossRef]

10. Dippong, T.; Cadar, O.; Levei, E.A.; Deac, I.G. Microstructure, porosity and magnetic properties of Zn0.5Co0.5Fe2O4/SiO2 nanocomposites prepared by sol-gel method using different polyols. J. Magn. Magn. Mater. 2020, 498, 166168. [CrossRef]

11. Rahimian-Koloor, S.M.; Moshrefzadeh-Sani, H.; Hashemianzadeh, S.M.; Shokrieh, M.M. The effective stiffness of an embedded graphene in a polymeric matrix. Curr. Appl. Phys. 2018, 18, 559-566. [CrossRef]

12. Shokrieh, M.M.; Esmkhani, M.; Haghighatkhah, A.R. Mechanical properties of graphene/epoxy nanocomposites under static and flexural fatigue loadings. Mech. Adv. Compos. Struct. 2014, 1, 3. [CrossRef]

13. Shokrieh, M.M.; Esmkhani, M.; Shahverdi, H.R.; Vahedi, F. Effect of Graphene Nanosheets (GNS) and Graphite Nanoplatelets (GNP) on the mechanical properties of epoxy nanocomposites. Sci. Adv. Mater. 2013, 5, 260-266. [CrossRef] 
14. Shokrieh, M.M.; Esmkhani, M.; Shokrieh, Z.; Zhao, Z. Stiffness prediction of graphene nanoplatelet/epoxy nanocomposites by a combined molecular dynamics-micromechanics method. Comput. Mater. Sci. 2014, 92, 444-450. [CrossRef]

15. Shokrieh, M.M.; Ghoreishi, S.M.; Esmkhani, M.; Zhao, Z. Effects of graphene nanoplatelets and graphene nanosheets on fracture toughness of epoxy nanocomposites. Fatigue Fract. Eng. Mater. Struct. 2014, 37, 1116-1123. [CrossRef]

16. Shokrieh, M.M.; Esmkhani, M.; Haghighatkhah, A.R.; Zhao, Z. Flexural fatigue behavior of synthesized graphene/carbonnanofiber/epoxy hybrid nanocomposites. Mater. Des. 2014, 62, 401-408. [CrossRef]

17. Sadeghpour, E.; Guo, Y.; Chua, D.; Shim, V.P.W. A modified Mori-Tanaka approach incorporating filler-matrix interface failure to model graphene/polymer nanocomposites. Int. J. Mech. Sci. 2020, 180, 105699. [CrossRef]

18. Arthisree, D.; Madhuri, W. Optically active polymer nanocomposite composed of polyaniline, polyacrylonitrile and greensynthesized graphene quantum dot for supercapacitor application. Int. J. Hydrogen Energy 2020, 45, 9317-9327. [CrossRef]

19. Bayat, A.; Saievar-Iranizad, E. Synthesis of green-photoluminescent single layer graphene quantum dots: Determination of HOMO and LUMO energy states. J. Lumin. 2017, 192, 180-183. [CrossRef]

20. Qu, D.; Zheng, M.; Zhang, L.; Zhao, H.; Xie, Z.; Jing, X.; Haddad, R.E.; Fan, H.; Sun, Z. Formation mechanism and optimization of highly luminescent $\mathrm{N}$-doped graphene quantum dots. Sci. Rep. 2014, 4, 5294. [CrossRef]

21. Teymourinia, H.; Salavati-Niasari, M.; Amiri, O.; Safardoust-Hojaghan, H. Synthesis of graphene quantum dots from corn powder and their application in reduce charge recombination and increase free charge carriers. J. Mol. Liq. 2017, 242, 447-455. [CrossRef]

22. Wang, Z.; Yu, J.; Zhang, X.; Li, N.; Liu, B.; Li, Y.; Wang, Y.; Wang, W.; Li, Y.; Zhang, L.; et al. Large-scale and controllable synthesis of graphene quantum dots from rice husk biomass: A comprehensive utilization strategy. ACS Appl. Mater. Interfaces 2016, 8 , 1434-1439. [CrossRef] [PubMed]

23. Zhuo, Q.; Gao, J.; Peng, M.; Bai, L.; Deng, J.; Xia, Y.; Ma, Y.; Zhong, J.; Sun, X. Large-scale synthesis of graphene by the reduction of graphene oxide at room temperature using metal nanoparticles as catalyst. Carbon 2013, 52, 559-564. [CrossRef]

24. Smith, A.T.; LaChance, A.M.; Zeng, S.; Liu, B.; Sun, L. Synthesis, properties, and applications of graphene oxide/reduced graphene oxide and their nanocomposites. Nano Mater. Sci. 2019, 1, 31-47. [CrossRef]

25. Tian, P.; Tang, L.; Teng, K.S.; Lau, S.P. Graphene quantum dots from chemistry to applications. Mater. Today Chem. 2018, 10, 221-258. [CrossRef]

26. Yan, Y.; Gong, J.; Chen, J.; Zeng, Z.; Huang, W.; Pu, K.; Liu, J.; Chen, P. Recent advances on graphene quantum dots: From chemistry and physics to applications. Adv. Mater. 2019, 31, 1-22. [CrossRef]

27. Gobi, N.; Vijayakumar, D.; Keles, O.; Erogbogbo, F. Infusion of graphene quantum dots to create stronger, tougher, and brighter polymer composites. ACS Omega 2017, 2, 4356-4362. [CrossRef]

28. ASTM International. Standard Test Methods for Flexural Properties of Unreinforced and Reinforced Plastics and Electrical Insulating Materials; ASTM D790-17; ASTM International: West Conshohocken, PA, USA, 2017.

29. Ahmadian-Fard-Fini, S.; Salavati-Niasari, M.; Ghanbari, D. Hydrothermal green synthesis of magnetic Fe3O4-carbon dots by lemon and grape fruit extracts and as a photoluminescence sensor for detecting of E. coli bacteria. Spectrochim. Acta A 2018, 203, 481-493. [CrossRef]

30. Ahmadian-Fard-Fini, S.; Ghanbari, D.; Salavati-Niasari, M. Photoluminescence carbon dot as a sensor for detecting of Pseudomonas aeruginosa bacteria: Hydrothermal synthesis of magnetic hollow NiFe2O4-carbon dots nanocomposite material. Compos. Part B-Eng. 2019, 161, 564-577. [CrossRef]

31. Ahmadian-Fard-Fini, S.; Ghanbari, D.; Amiri, O.; Salavati-Niasari, M. Electro-spinning of cellulose acetate nanofibers/Fe/carbon dot as photoluminescence sensor for mercury (II) and lead (II) ions. Carbohydr. Polym. 2020, 229, 115428. [CrossRef]

32. Shams, H.R.; Ghanbari, D.; Salavati-Niasari, M.; Jamshidi, P. Solvothermal synthesis of carbon nanostructure and its influence on thermal stability of poly styrene. Compos. Part B Eng. 2013, 55, 362-367. [CrossRef]

33. Ebadi, M.; Mirdamadian, Z.; Ghanbari, D.; Moradi, L. The effect of aminated carbon nanotube and phosphorus pentoxide on the thermal stability and flame retardant properties of the acrylonitrile-butadiene-styrene. J. Clust. Sci. 2014, 25, 541-548. [CrossRef]

34. Mirdamadian, Z.; Ghanbari, D. Synergistic effect between Sb2O3 nanoparticles-Trichloromelamine and carbon nanotube on the flame retardancy and thermal stability of the cellulose acetate. J. Clust. Sci. 2014, 25, 925-936. [CrossRef]

35. Liu, H.Y.; Wang, G.; Mai, Y.W. Cyclic fatigue crack propagation of nanoparticle modified epoxy. Compos. Sci. Technol. 2012, 72, 1530-1538. [CrossRef]

36. Shokrieh, M.M.; Saeedi, A.; Chitsazzadeh, M. Mechanical properties of multi-walled carbon nanotube/polyester nanocomposites. J. Nanostruct. Chem. 2013, 3, 20. [CrossRef]

37. Shokrieh, M.M.; Saeedi, A.; Chitsazzadeh, M. Evaluating the effects of multi-walled carbon nanotubes on the mechanical properties of chopped strand mat/polyester composites. Mater. Des. 2014, 56, 274-279. [CrossRef] 